\title{
Biotech drug market steadily expands
}

\author{
Stacy Lawrence
}

Unlike last year's billion dollar approvals, Avastin (bevacizumab) and Erbitux (cetuximab), no biotech blockbusters were launched in 2005 and none appear to be on the horizon. Almost half of the biologics license applications pending at the US Food and Drug Administration (FDA) are for supplementary indications (for drugs already on the

\section{Investigational biotech drugs by area}

Cancer continues to dominate, closely followed by AIDS and other infectious diseases. Drug delivery research gets considerable attention.

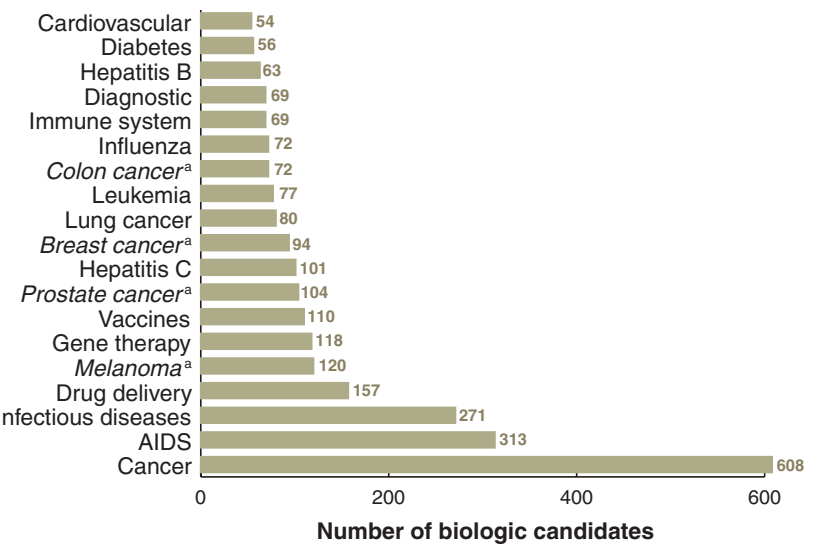

aCancer subtype broken out from total cancer. Source: BioPharm Insight

\section{Biotech drug applications}

Of the pending/expected biologic license applications (BLAs), almost onethird are for supplementary indications; unlike 2004, none of the new applications is for projected blockbusters.

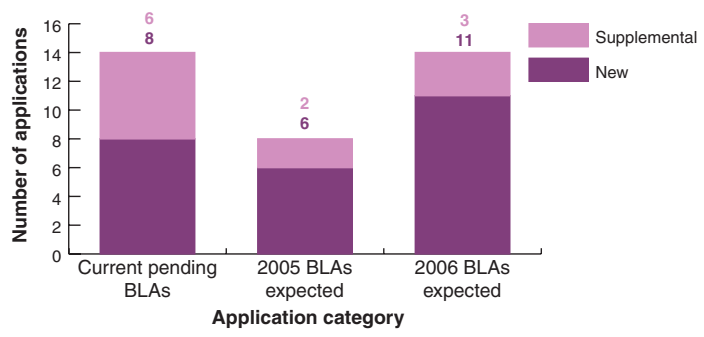

Data as of October 2005, based on FDA BLA applications. Source:SG Cowen

\section{Public biotech sales and R\&D}

Biotech sales continue to grow in the double digits, but research spending has leveled off.

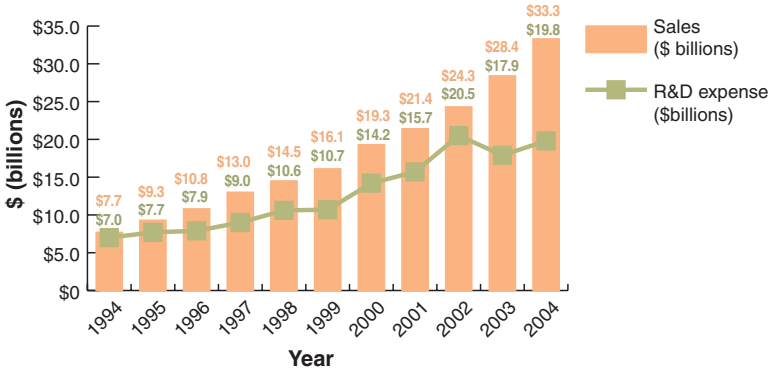

Based on public company data. Source: Ernst \& Young market). Certain biotech therapies are among the fastest growing drug market segments (mAbs sales grew by 52\% in 2005); five of the 20 best-selling drugs are large molecules. Biotech increasingly dominates the pipeline ( $44 \%$ of all discovery stage candidates) and has a growing share of drug applications (about one in ten of filings).

\begin{tabular}{lcccc}
\hline Top 10 biotech drugs by global sales & & & \\
\hline & $\begin{array}{l}2004 \text { sales } \\
\text { (\$ millions) }\end{array}$ & $\begin{array}{c}\text { Percent } \\
\text { change }\end{array}$ & $\begin{array}{c}\text { Annual } \\
\text { growth }^{\text {a }}\end{array}$ & $\begin{array}{c}2004 \\
\text { market share }\end{array}$ \\
\hline $\begin{array}{l}\text { Erypo/Procrit } \\
\text { (Johnson \& Johnson) }\end{array}$ & $\$ 3,989$ & $-4.2 \%$ & $23.0 \%$ & $9.0 \%$ \\
\hline $\begin{array}{l}\text { Epogen (Amgen) } \\
\text { Enbrel (Amgen/Wyeth) }\end{array}$ & $\$ 2,897$ & $-3.8 \%$ & $14.1 \%$ & $6.5 \%$ \\
\hline Aranesp (Amgen) & $\$ 2,569$ & $77.9 \%$ & $* * *$ & $5.8 \%$ \\
\hline $\begin{array}{l}\text { Remicade (Johnson \& } \\
\text { Johnson/Schering-Plough) }\end{array}$ & $\$ 2,506$ & $19.8 \%$ & $130.8 \%$ & $5.6 \%$ \\
\hline Mabthera/Rituxan (Roche) & $\$ 2,192$ & $24.4 \%$ & $62.7 \%$ & $4.9 \%$ \\
\hline Neulasta (Amgen) & $\$ 1,873$ & $52.1 \%$ & $* * *$ & $4.2 \%$ \\
\hline Avonex (Biogen Idec) & $\$ 1,383$ & $16.4 \%$ & $18.1 \%$ & $3.1 \%$ \\
\hline Neupogen (Amgen/Roche) & $\$ 1,344$ & $-6.8 \%$ & $2.5 \%$ & $3.0 \%$ \\
\hline Lantus (Aventis) & $\$ 1,014$ & $80.9 \%$ & $* * *$ & $2.3 \%$ \\
\hline Total top 10 & $\$ 22,346$ & $20.7 \%$ & $31.3 \%$ & $50.4 \%$ \\
\hline Global biotech market & $\$ 44,353$ & $17.0 \%$ & $21.6 \%$ & $100.0 \%$ \\
\hline
\end{tabular}

aCompound annual growth 1999-2003. Source:IMS Health

Potential blockbusters in the pipeline

\begin{tabular}{|c|c|c|c|c|}
\hline Company & $\begin{array}{l}\text { Generic } \\
\text { name }\end{array}$ & Type & Indication & $\begin{array}{l}\text { Annual sales } \\
(\$ \text { millions })^{a}\end{array}$ \\
\hline Amylin/Lilly & Exenatide $^{b}$ & Peptide & Type II diabetes & $\$ 1000+$ \\
\hline Onyx/Bayer & Sorafenib & Small molecule & Kidney cancer & $\$ 500-1000$ \\
\hline CV Therapeutics & Ranolazine & Small molecule & Chronic angina & $\$ 400-500$ \\
\hline MGI/Supergen & Decitabine & Small molecule & $\begin{array}{l}\text { Myelodysplastic } \\
\text { syndrome }\end{array}$ & $\$ 300-500$ \\
\hline Cephalon & Modafenil & Small molecule & $\begin{array}{l}\text { Pediatric attention } \\
\text { deficit/hyperactivity } \\
\text { disorder }\end{array}$ & $\$ 300-500$ \\
\hline Celgene & Lenalidomide & Small molecule & MDS and myeloma & $\$ 300-500$ \\
\hline Cephalon & Naltrexone & Small molecule & Alcoholism & $\$ 300-500$ \\
\hline NPS & Preos & $\begin{array}{l}\text { Recombinant } \\
\text { hormone }\end{array}$ & Osteoporosis & $\$ 300-500$ \\
\hline
\end{tabular}

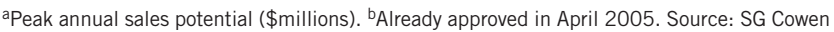

\section{Biotech drug candidates by phase}

More than 2,500 large molecules in discovery represents $40 \%$ of all drug candidates.

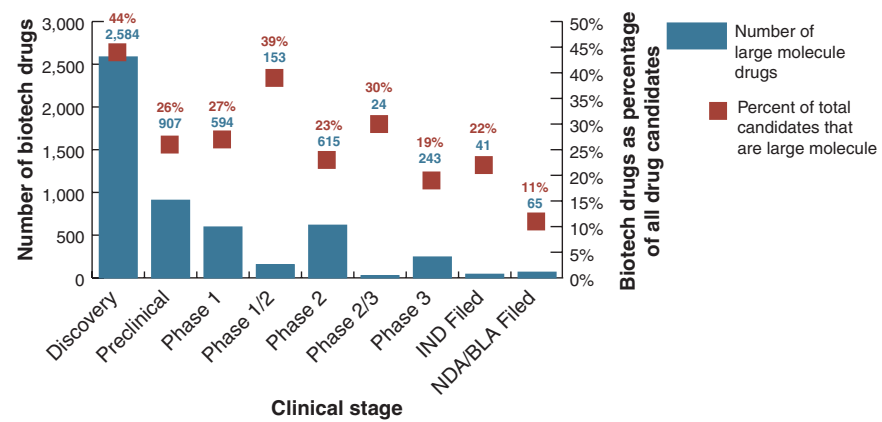

Source: Biopharm Insight 